\title{
Anti COVID-19 Drug - Potential Bioactive Compounds from Sprout Shoots of Curcuma longa Rhizome and Molecular Interaction Studies
}

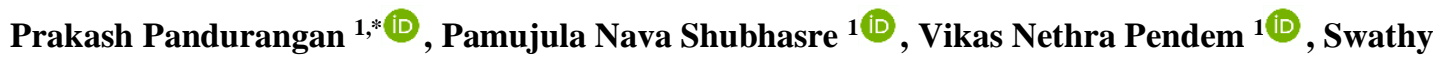 \\ Thirunavukkarasu $^{1}$ (D), Suriyaraj Senthilrajan ${ }^{1}$ (D), Sai Nandhini Ravi ${ }^{2}{ }^{(D)}$, Narendrakumar \\ Gopakumaran 1 ${ }^{\text {(D) , Praveena Ravanappan }}{ }^{3}$ (D) \\ 1 Department of Biotechnology, School of Bio and Chemical Engineering. Sathyabama Insitute of Science and Technology, \\ Chennai, Tamilnadu India \\ 2 Department of Biotechnology, Vel Tech Rangarajan Dr. Sagunthala R\&D Institute of Science and Technology, Avadi, \\ Chennai India \\ 3 Siddha Physician, Chennai, India \\ * Correspondence: kpprakashmtech@gmail.com (P.P.);
}

Scopus Author ID 43861752900

Received: 2.08.2021; Revised: 10.09.2021; Accepted: 15.09.2021; Published: 17.10.2021

\begin{abstract}
India is currently fighting against the deadly contagious, Novel coronavirus (nCoV) in all possible means. Though many antiviral drugs are available in the mainstream treatment for respiratory viral infections, no targeted antiviral has been identified, and vaccine trials are ongoing. The traditional system of medicine possesses a broad range of scope to bridge the gaps in treatment methods and the time lag between vaccine developments. There may be a chance of mutation of the virus, drug resistance, etc. The present study reports metabolites profiling from the shoot of Curcuma longa, and the LCMS method was used to characterize phytochemical in which sixteen compounds were screened and used for the active site of the SARS CoV-2 spike protein using Autodock 4.2.6. The three dimensions crystal structure PDB id was retrieved from PDB, and the active sites were predicted using metapocket 2.0. Binding affinity data and interaction patterns revealed that these compounds could inhibit the development of disease inside the body system, and it can be used to design different nutraceutical and pharmaceuticals.. https://orcid.org/0000-0002-5377-8129
\end{abstract}

Keywords: secondary metabolites; docking; coronavirus.

(C) 2021 by the authors. This article is an open-access article distributed under the terms and conditions of the Creative Commons Attribution (CC BY) license (https://creativecommons.org/licenses/by/4.0/).

\section{Introduction}

A highly contagious disease COVID-19 was caused by the novel coronavirus SARSCoV-2 (Severe acute respiratory syndrome coronavirus 2) [1]. The disease has recently become a pandemic across the globe. It is an enveloped virus with a positive sense, single-stranded RNA genome transmitted via respiratory droplets. SARS-CoV-2 consists of four major structural proteins - spike (S) protein, envelope protein, nucleocapsid protein, and membrane protein [2]. The SARS-CoV-2 invades and affects the host cell by undergoing certain modifications. After that, it binds to the ACE2 (Angiotensin-Converting Enzyme 2) receptor in the alveoli of lungs, heart, brain, kidney, intestine, liver, pharynx, and respiratory epithelium in humans. It can cause damage to these organs [3].

The S-protein belongs to the Class-I fusion protein present within the envelope as a homo-trimer and consists of three S1-S2 heterodimers. Mutations in Spike protein (S) are of 
specific concern, like S, through the Receptor Binding Domin (RDB), directs cellular tropism and is the target for the nullify antibody response. Mutations in Spike could therefore enhance viral fitness by increasing affinity to ACE2 or provide an escape from the antibody response prevailed upon by natural infection or inducing immunity by vaccination $[4,5]$.

Since the immune conditions play a significant role in COVID-19 infected patients, an herbal-based medicine that controls an immunomodulatory activity has a potential therapeutic source for preventing and treating COVID-19 infection [6]. Curcuminoids are the key ingredient of Curcuma longa L. (Turmeric). The yellow color of turmeric is one of the major curcuminoids, curcumin, which has been used for centuries in several biological systems characteristics due to its pharmacological wellbeing [7]. Curcumin has many attributes, such as acting against ischemia-reperfusion injury in cardiomyocytes by inhibiting autophagy and apoptosis [8] antioxidant and anti-inflammatory property [9]. Natural products have been used in conventional treatments for thousands of years and have shown potential as a source of components for the advancement of new drugs.

Curcuma longa is a member of the Zingiberaceae plant family and is cultivated worldwide, starting from India, Southeast Asia, and Indonesia. The dry extracted powder of Curcuma longa is used significantly as a coloring and flavoring agent in curries and mustards in many countries. Turmeric has been used in India to sustain digestive hygiene. It has conventionally been used for treatment reasons from ancient times in countries such as India and China to cure jaundice and other liver-related ailments. Turmeric is an accepted medicinal herb, with a wide range of pharmacological accomplishments such as antioxidant [10], antiprotozoal [11], anti-venom activities [12], anti-microbial [13] anti-malarial [14], antiinflammatory [6], anti-proliferative [15], anti-angiogenic [16], anti-tumor [17] and anti-aging [8] properties. It has also been used to treat various skin diseases, anti-immune diseases, parasitic infections, ulcers, and curing the symptoms of colds and flu. [11]

Curcuma longa $\mathrm{L}$. is popular worldwide because of culinary cosmetics and medicinal uses, and it can inhibit main protease enzymes, thereby preventing life-threatening viral disease COVID19. The rhizome contains two major products Curcumids and essential oils [18]. The existing drug has certain adverse effects, so it is necessary to find a natural remedy for prophylaxis and treatment of COVID-19 [19]. The Curcuma longa turmeric is a natural product for curing many diseases. Curcumin is a ligand of peroxisome proliferator-activated receptor$\gamma$, which constrains the inflammatory mechanism by diminishing the cytokine production; therefore, it might play an analogous role in protecting against lung damage related to COVID19 [20].

The L. rhizome is a classic medicine, which has been used for many years for antimicrobial, antioxidants, anti-inflammatory, antidiabetic, antiplatelets aggregate, and anticancer [21]. The plant's highlight is that all parts of the plants have significant biological compounds such as curcumin, several phenolic compounds, and flavonoids; the root is rich in anti-inflammatory and antioxidants [22]. In most traditional medicines, turmeric has an important role because turmeric has plenty of health benefits. Hence, many traditional medicines have been suggested for SARS Covid -19. In this medicine also turmeric has been added as an important compound because of antiviral activity. Different studies have shown that the plant compounds inhibit the virus-receptor interaction with the spike protein and the ACE2 receptor [23]. 


\section{Materials and Methods}

\subsection{Plant materials and extraction.}

The collected samples were washed with running tap water to remove the dust and dried preserved until it was used for the extraction.

\subsection{Solvent extraction.}

$5 \mathrm{~g}$ of dried sample was taken in two conical flasks. $50 \mathrm{ml}$ of methanol and $50 \mathrm{ml}$ of distilled water are added to the two flasks, respectively. The soaked sample is placed in the shaker and incubated for three days. Then the sample was taken out from the shaker and centrifuged for $10 \mathrm{~min}$. The supernatant from the methanolic extract was taken and evaporated in a Soxhlet Apparatus, and 1- $2 \mathrm{ml}$ of methanol was supplemented, and the crude sample was prepared to 1-2 $\mathrm{ml}$. The aqueous sample was taken, and the same process was repeated with distilled water replacing methanol [17].

\subsection{Liquid chromatography-mass sample spectrometry analysis.}

The extracted sample will be analyzed by using Agilent 6530 Accurate-Mass Q-TOF liquid chromatography-mass sample spectrometry (LC-MS) system with Agilent Zorbax Eclipse XDB-C18 column $(2.1 \times 50 \mathrm{~mm}, 1.8$ microns $)$, eluted with a mixture of acetonitrile and water as gradient system. The mobile phase began with $99.5 \%$ of water and decreased to $50 \%$ of water over $10 \mathrm{~min}$, followed by $50 \%$ of water and decreased to $0 \%$ over $25 \mathrm{~min}$ and then held at $0 \%$ of water for $5 \mathrm{~min}$ and finally increased to $99.5 \%$ of water over $3 \mathrm{~min}$ at a flow rate of $0.25 \mathrm{~mL} / \mathrm{min}$. The test will be performed in the positive ion mode. The drying gas flow rate will be set at $8 \mathrm{~L} / \mathrm{min}$ at the temperature of $350{ }^{\circ} \mathrm{C}$. The nebulizer pressure will be set at 35 PSIG with the capillary and injection volume set at $3000 \mathrm{~V}$ and $5 \mu \mathrm{L}$, respectively [24,25].

\subsection{Determination of ligands.}

The selection of Curcuma longa compounds used as ligands in the docking process in this study was based on the in-vitro and in-silico experiments[26]. The information was obtained from LC-MS results - Germacrone, $\alpha$-Turmerone, Levomenol, $\beta$-Turmerone (curlone), zingiberenol, Farnesyl acetate, Germacrene Nerolidol, sesquisabinene hydrate, eucalyptol, curcumene terpinolene, $\alpha$-phellandrene, $\beta$-cymene Ascaridole, Citral, Arachidonic acid.

\subsection{System information.}

The following software were used in the present study: 1) AutoDock 4.2.6 2) Python 3.8.2 3) MGLTools 1.5.4 4) Discovery Studio visualizer 3.5 5) UCSF Chimera 1.13.1, 6) LigPlotpv.2.2, 7) Java Platform SE binary version 8, and 8) PyMOL 2 [27]. The following were the system properties with which the study was conducted. Processor: Intel(R) Core(TM) i5-9300HF CPU @ 2.40GHz, System memory: 4 GB RAM, system type:64-bit operating system, Windows 10 as Operating System. 
2.6. Retrieval of SARS - CoV-2 protein.

The crystal structure SARS-CoV-2 B.1.351 variant -7NXA RCSB Protein Data Bank (PDB) (https://www.rcsb.org/). The protein was in a complex with. Water molecules, inhibitors, and other heteroatoms from the protein were removed and used for docking [28].

\subsection{Ligand and receptor preparation.}

The \#D structure of 7NXA was retrieved from RCSB PDB in pdb format. The protein served as a receptor in the docking process the files were opened in UCSF Chimera Water molecules, and the ligand that was attached to the receptors was removed. Subsequently, the files were saved in the mol 2 and pdbqt formats[4,29,30].

Ligand structures were acquired from the PubChem site. The search was executed by entering the Canonical smiles of the ligand in the search option (Table 1). Each ligand's file was downloaded and saved separately. Files in the *.*sdf format were converted to **pdb using Open Babel. The PubChem CID or the Canonical smiles can be used to retrieve the structure of the ligand in Chimera using the build structure option. Further, the energy minimization was performed using tools - structure edition - minimize structure option [3133].

Table 1. Summary of computed in silico "drug-likeness" properties of compounds from PubChem.

\begin{tabular}{l|l}
\multicolumn{1}{c|}{ Compounds } & \multicolumn{1}{c}{ SMILES } \\
\hline Germacrone & $\mathrm{CC} 1=\mathrm{CCC}(=\mathrm{C}(\mathrm{C}) \mathrm{C}) \mathrm{C}(=\mathrm{O}) \mathrm{CC}(=\mathrm{CCC} 1) \mathrm{C}$ \\
\hline$\alpha$-Turmerone & $\mathrm{CC} 1=\mathrm{CCC}(\mathrm{C}=\mathrm{C} 1) \mathrm{C}(\mathrm{C}) \mathrm{CC}(=\mathrm{O}) \mathrm{C}=\mathrm{C}(\mathrm{C}) \mathrm{C}$ \\
\hline Levomenol & $\mathrm{CC} 1=\mathrm{CCC}(\mathrm{CC} 1) \mathrm{C}(\mathrm{C})(\mathrm{CCC}=\mathrm{C}(\mathrm{C}) \mathrm{C}) \mathrm{O}$ \\
\hline$\beta$-Turmerone (curlone) & $\mathrm{CC}(\mathrm{CC}(=\mathrm{O}) \mathrm{C}=\mathrm{C}(\mathrm{C}) \mathrm{C}) \mathrm{C} 1 \mathrm{CCC}(=\mathrm{C}) \mathrm{C}=\mathrm{C} 1$ \\
\hline Zingiberenol & $\mathrm{CC}(\mathrm{CCC}=\mathrm{C}(\mathrm{C}) \mathrm{C}) \mathrm{C} 1 \mathrm{CCC}(\mathrm{C}=\mathrm{C} 1)(\mathrm{C}) \mathrm{O}$ \\
\hline Farnesyl acetate & $\mathrm{CC}(=\mathrm{CCCC}(=\mathrm{CCCC}(=\mathrm{CCOC}=\mathrm{O}) \mathrm{C}) \mathrm{C}) \mathrm{C}) \mathrm{C}$ \\
\hline Germacrene & $\mathrm{CC} 1=\mathrm{CCCC}(=\mathrm{CCC}(\mathrm{CC} 1) \mathrm{C}=\mathrm{C}) \mathrm{C}) \mathrm{C}$ \\
\hline Nerolidol & $\mathrm{CC}(=\mathrm{CCCC}(=\mathrm{CCCC}(\mathrm{C})(\mathrm{C}=\mathrm{C}) \mathrm{O}) \mathrm{C}) \mathrm{C}$ \\
\hline Sesquisabinene hydrate & $\mathrm{CC}(\mathrm{CCC}=\mathrm{C}(\mathrm{C}) \mathrm{C}) \mathrm{C} 12 \mathrm{CCC}(\mathrm{C} 1 \mathrm{C} 2)(\mathrm{C}) \mathrm{O}$ \\
\hline Eucalyptol & $\mathrm{CC} 1(\mathrm{C} 2 \mathrm{CCC}(\mathrm{O} 1)(\mathrm{CC} 2) \mathrm{C}) \mathrm{C}$ \\
\hline Curcumene & $\mathrm{CC} 1=\mathrm{CC}=\mathrm{C}(\mathrm{C}=\mathrm{C} 1) \mathrm{C}(\mathrm{C}) \mathrm{CCC}=\mathrm{C}(\mathrm{C}) \mathrm{C}$ \\
\hline Terpinolene & $\mathrm{CC} 1=\mathrm{CCC}(=\mathrm{C}(\mathrm{C}) \mathrm{C}) \mathrm{CC} 1$ \\
\hline$\beta$-cymene & $\mathrm{CC} 1=\mathrm{CC}(=\mathrm{CC}=\mathrm{C} 1) \mathrm{C}(\mathrm{C}) \mathrm{C}$ \\
\hline Ascaridole & $\mathrm{CC}(\mathrm{C}) \mathrm{C} 12 \mathrm{CCC}(\mathrm{C}=\mathrm{C} 1)(\mathrm{OO} 2) \mathrm{C}$ \\
\hline Citral & $\mathrm{CC}(=\mathrm{CCCC}(=\mathrm{CC}=\mathrm{O}) \mathrm{C}) \mathrm{C}$ \\
\hline Arachidonic acid & $\mathrm{CCCCCC}=\mathrm{CCC}=\mathrm{CCC}=\mathrm{CCC}=\mathrm{CCCCC}(=\mathrm{O}) \mathrm{O}$
\end{tabular}

\subsection{Insilco drug-likeness.}

Properties of active compounds were calculated using Lipinski's rule of five (ro5), is often studied as the use test for the assessment of oral availability for compounds in the early stage of drug discovery protocol calculated on the SWISSADME predictor (http://www.swissadme.ch/) and confirmed using (http://molsoft.com/mprop/) Molsoft L.L.C. (Molecular Properties and Drug-likeness) [34]

In summary, Lipinski's ro5 describes an orally obtainable molecule as one for which the Molecular Weight is less than 500 Daltons $(\mathrm{Da}), \log \mathrm{P} \leq \mathrm{HBA} \leq 10$, and $\mathrm{HBD} \leq 5$. Another rule for the NRB is frequently added to this ro5, such that NRB $\leq 5$ is to take drug metabolism and pharmacokinetics (DMPK) profiles into an important factor. 


\subsection{Active-site determination.}

The amino acid positions of an active site in the protein (receptor) region where the ligand was docked were analyzed using Autodock tools. The target docking was performed using the grid box in the three-dimensional map.

\subsection{Docking simulations.}

The workspace for preparing the grid (.gpf) and Docking (.dpf) process files was performed using the AutoDockTools 1.5.3 GUI.

The grid box was adjusted to center on 7NXA and confined to the binding pocket of the target and then saved in the *.*gpf file format. The docking parameter file (DPF) was constructed using the Docking option menu employing the Lamarckian Genetic Algorithms (LGA) with the specific docking parameters given by the software. Fifty search attempts using Genetic Algorithm run parameters were executed for sixteen ligands. Fifty conformations of ligand in the protein complex with the receptor were obtained that were ranked based on binding energy. The final conformations were pictured in the Discovery Studio Visualizer and PyMol [35,36].

To implement the procedure for docking spike protein of SARS-CoV to the sit of binding, the ligands identified from the plants present inside each protein-ligand complexes' binding pocket were docked towards their respective receptor sites using different grid parameters. In an attempt to identify the best docking parameters which reproduce the ligand conformation (docking poses) within the binding pocket, with the lowest RMSD values, concerning the experimental binding mode [37].

Docking experiments were executed using the AutoDock Tools 1.5.3 docking interface to discover the desired binding conformations of the ligands in the 7NAX. The testing of the binding confirmation was carried out using the affinity scoring based on the free energy of binding theory - more negative value means more binding affinity [38].

\section{Results and Discussion}

\subsection{Extraction and LC-MS.}

The extract was subjected to LC-MS, and the following peaks were observed (Figure 1) from the profile the compounds were selected.

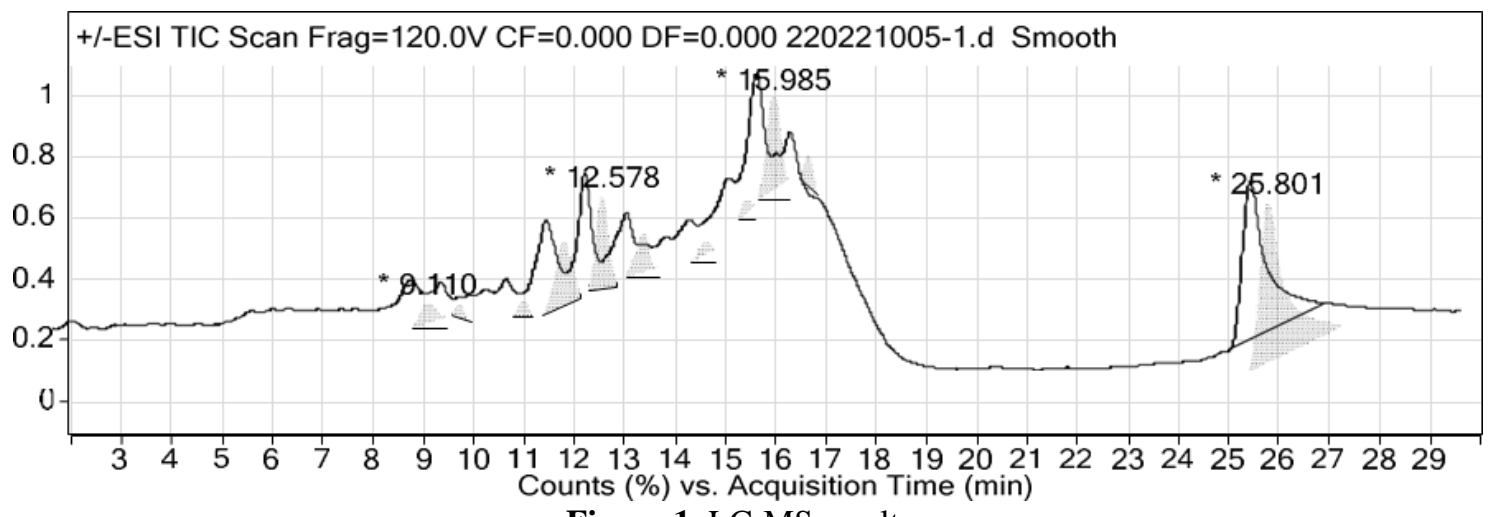

Figure 1. LC-MS results.

In the view of identifying more rational drug discovery methodologies to acquiesce the leads against the viral protein, there is always a justification for examining Curcuma longa 
products. Germacrone, $\alpha$-Turmerone, Levomenol, $\beta$-Turmerone (curlone), zingiberenol, Farnesyl acetate, Germacrene Nerolidol, sesquisabinene hydrate, eucalyptol, curcumene terpinolene, $\alpha$-phellandrene, $\beta$-cymene Ascaridole, Citral, Arachidonic acid were selected for the docking as it was fulfilling the Lipinski's Rule of Five. These values of the docking compounds computed on the SWISSADME predictor and Molsoft is presented in Table 2. Most of the compounds tested in this investigation do not violate the Ro5. It is defined as orally available molecules as one of which the MW is lesser than $500 \mathrm{Da}, \log \mathrm{P}$ is less than 5 , and HBA is less than 10, and HBD is less than five. The property of the molecular size and its ability to make hydrogen bonds, its overall lipophilicity, and its flexibility play a significant role in identifying the permeability. Molecular flexibility is another important parameter, and it depends on the NRB.

Table 2. Druglikeness using SWISSADME.

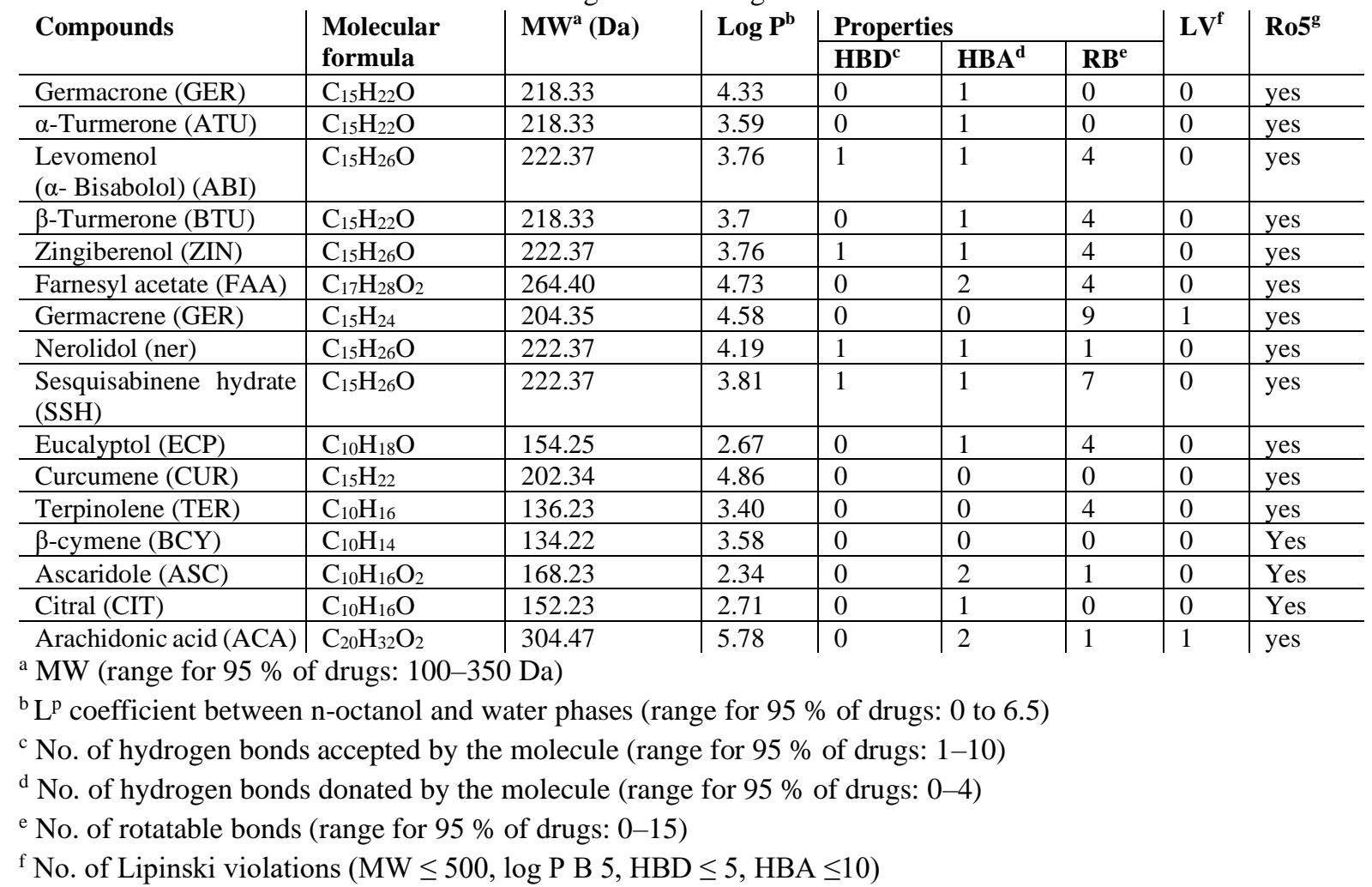

\subsection{Retrieval of SARS - CoV-2 protein.}

The crystal structure of the RBD of SARS-CoV-2 B.1.351 variant -7NXA - Spike glycoprotein in complex with COVOX-2 and EY6A Fabs was recovered from the RCSB Protein Data Bank (PDB) (https://www.rcsb.org/). 7NXA is a protein complex with an inhibitor. The heteroatoms, water molecules, and inhibitors from the protein complex were deleted, and core protein was used for docking [28].

The interaction of spike protein with that of the compounds in the present study was carried out after removing the Fabs protein (EY6A) from the structure, as this would free the binding site for interaction.

\subsection{Docking of ligands against the target.}

The docking method implicated the best docking parameters essential to imitate the ligand positioning within the target's binding site followed by the calculation of the ligand 
conformation and orientation within a target binding site of the identified Curcuma longa compounds and comparing with those between the target and the ligand.

Table 3. Graphical representation of drug-likeness and violations
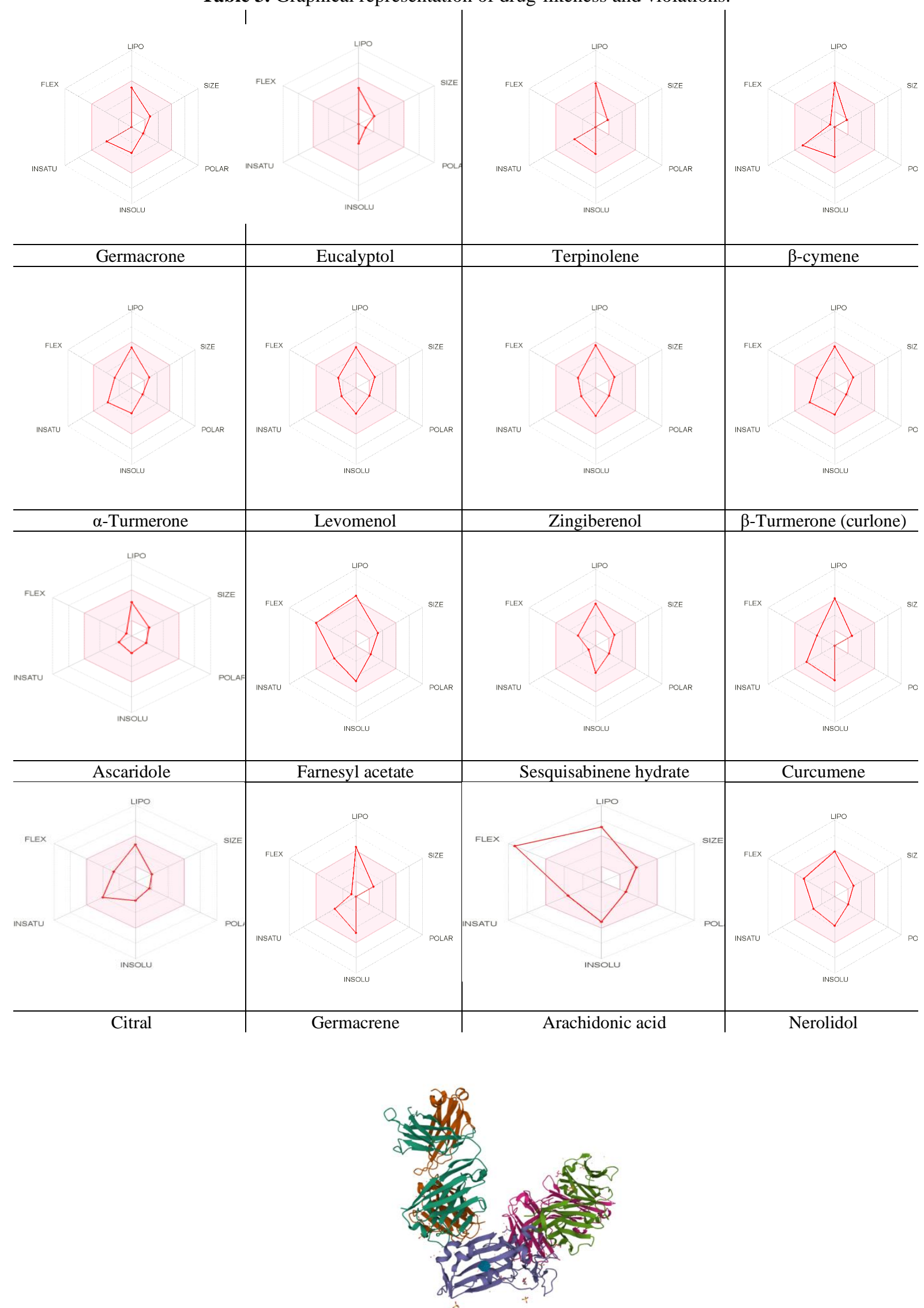

Figure 2. Crystal structure of the RBD of SARS-CoV-2 B.1.351 variant -7NXA - Spike protein S1 and EY6A Fabs heavy chain. 
The assessment of free energy of binding among possible inhibitors and receptors was achieved using docking trials. Table 3 and Figure 3 illustrate the docking results between the specific compounds and S-protein. The docking values revealed that few ligands from Curcuma longa with better binding positions with S-protein are Germacrone, $\alpha$-Turmerone, Levomenol, $\beta$-Turmerone (curlone), zingiberenol, Farnesyl acetate, Germacrene Nerolidol, sesquisabinene hydrate, eucalyptol, curcumene terpinolene, $\alpha$-phellandrene, $\beta$-cymene Ascaridole, Citral, Arachidonic acid in which few compounds disclosed better binding poses.

\subsection{Docking validation.}

To calculate the docking values that can be interpreted, authentication was carried out by docking again with the receptor and ligands using another software.

Table 4. Grid position.

\begin{tabular}{|c|c|c|c|c|c|c|c|c|c|}
\hline \multirow[t]{2}{*}{ Trials } & \multirow[t]{2}{*}{ Protein-ligand complex } & \multicolumn{3}{|c|}{ GridPoint $\left(\mathbf{A}^{\mathbf{0}}\right)$} & \multicolumn{3}{|c|}{ Center of Grid box } & \multirow{2}{*}{$\begin{array}{l}\text { Binding } \\
\text { Energy } \\
\text { (kcal/ mol) }\end{array}$} & \multirow[t]{2}{*}{ RMSD } \\
\hline & & $\mathbf{X}$ & $\mathbf{Y}$ & $\mathbf{Z}$ & $\mathbf{X}$ & $\mathbf{Y}$ & $\mathbf{Z}$ & & \\
\hline 1 & 7NAX_SP_ABI & 32 & 18 & 14 & 0.04 & -0.83 & 0.078 & 2.75 & -3.39 \\
\hline 2 & 7NAX_SP_ACA & 64 & 16 & 20 & 0.76 & 0.07 & -.033 & 3.47 & 4.21 \\
\hline 3 & 7NAX_SP_ASC & 44 & 20 & 26 & 1.41 & -0.21 & -0.88 & 2 & 3.01 \\
\hline 4 & 7NAX_SP_ATU & 40 & 28 & 20 & -0.10 & -0.8 & 0.196 & 1.86 & -3.55 \\
\hline 5 & 7NAX_SP_BCY & 32 & 20 & 24 & 1.03 & -0.27 & -0.87 & 2.34 & -3.56 \\
\hline 6 & 7NAX_SP_BTU & 30 & 14 & 16 & -0.19 & -0.01 & -0.23 & 1.38 & -4.06 \\
\hline 7 & 7NAX_SP_CIT & 31 & 16 & 21 & -0.08 & -0.02 & 0.871 & 3.26 & -4.19 \\
\hline 8 & 7NAX_SP_CUR & 36 & 14 & 12 & .076 & 0.19 & -0.72 & 2.01 & -4.4 \\
\hline 9 & 7NAX_SP_ECP & 16 & 14 & 16 & 0.422 & -0.15 & 0.983 & 4.25 & -3.21 \\
\hline 10 & 7NAX_SP_FAA & 28 & 20 & 16 & -0.19 & -0.54 & -0.04 & 1.92 & -2.74 \\
\hline 11 & 7NAX_SP_GER & 32 & 26 & 22 & -0.61 & -0.14 & -0.42 & 3.29 & -3.61 \\
\hline 12 & 7NAX_SP_GRB & 24 & 24 & 16 & -0.92 & -0.75 & 0.005 & 4.57 & -3.27 \\
\hline 13 & 7NAX_SP_NER & 28 & 22 & 24 & 0.076 & 0.249 & -2.23 & 2.58 & -2.59 \\
\hline 14 & 7NAX_SP_SSH & 28 & 16 & 26 & -0.02 & -0.32 & -2.57 & 2.47 & -3.23 \\
\hline 15 & 7NAX_SP_TER & 36 & 22 & 18 & 0.988 & 0.295 & -0.37 & 4.48 & -2.74 \\
\hline 16 & 7NAX_SP_ZIN & 30 & 12 & 10 & -0.68 & -0.02 & -0.44 & 6.25 & -3.32 \\
\hline
\end{tabular}

\subsection{Validation of target protein-ligand complex structures.}

Validation was performed by docking the ligands identified from the LCMS data on the target protein using Chimera software. The docking scores will demonstrate the compounds with the least bond energy. This phenomenon will happen when it interacts with the 7NXA to obtain the docking compound's RMSD value. The approach is expressed to be effective if the RMSD value obtained is $\leq 2^{\circ} \mathrm{A}$, to ensure docking for the test compound can be carried out with the 7NXA in the grid box area that is the same.

\subsection{Analysis and visualization.}

The outcome of the docking computations was revealed in the output in notepad format. The docking conformation of the ligands was established by picking the pose with the highest value.

Table 5. Lowest energy docked conformation.

\begin{tabular}{l|c|c|c|r|c|c|c|c|c|c|c} 
& $\mathbf{R u n}$ & $\mathbf{C R}^{\mathbf{a}}$ & $\mathbf{N C C}$ & $\mathbf{R M S D}^{\mathbf{c}}$ & $\mathbf{B E}^{\mathbf{d}}$ & $\mathbf{F I E}^{\mathbf{e}}$ & $\mathbf{D E}^{\mathbf{f}}$ & $\mathbf{E E}^{\mathbf{g}}$ & $\mathbf{F T I E}^{\mathbf{h}}$ & $\mathbf{T E}^{\mathbf{i}}$ & $\mathbf{U B}^{\mathbf{j}}$ \\
\hline 7NAX_SP_CUR & 7 & 1 & 19 & 2.01 & -4.4 & -4.27 & -4.12 & -0.03 & -1.49 & -1.39 & 1.29 \\
\hline 7NAX_SP_CIT & 26 & 1 & 20 & 3.26 & -4.19 & -4.81 & -3.81 & -0.27 & -0.34 & -1.23 & -0.34 \\
\hline 7NAX_SP_BTU & 45 & 1 & 48 & 1.38 & -4.06 & -3.01 & -2.91 & -0.04 & 0.18 & 1.19 & -0.18 \\
\hline 7NAX_SP_GER & 21 & 1 & 48 & 3.29 & -3.61 & -3.25 & -3.14 & -0.41 & -0.27 & -0.32 & 0 \\
\hline 7NAX_SP_BCY & 39 & 1 & 50 & 2.34 & -3.56 & -3.11 & -2.95 & -0.01 & -0.14 & 0.3 & -0.14 \\
\hline 7NAX_SP_ATU & 22 & 1 & 7 & 1.86 & -3.55 & -3.14 & -3.02 & -0.12 & -0.04 & 0.25 & -0.14
\end{tabular}




\begin{tabular}{|c|c|c|c|c|c|c|c|c|c|c|c|}
\hline & Run & $\mathbf{C R}^{\mathrm{a}}$ & $\mathrm{NCC}^{\mathrm{b}}$ & RMSD $^{c}$ & $\mathbf{B E}^{\mathbf{d}}$ & FIE $^{\mathrm{e}}$ & $D E^{f}$ & $\mathbf{E E}^{\mathrm{g}}$ & FTIE $^{\text {h }}$ & $\mathbf{T E}^{\mathrm{i}}$ & $\mathbf{U B}^{\mathbf{j}}$ \\
\hline 7NAX_SP_ABI & 11 & 1 & 47 & 2.75 & -3.39 & -3.25 & -3.14 & -0.25 & -0.14 & -0.25 & -0.25 \\
\hline 7NAX_SP_ZIN & 4 & 1 & 32 & 6.25 & -3.32 & -3.12 & -3.02 & -0.18 & -0.04 & -0.02 & -0.14 \\
\hline 7NAX_SP_GRB & 30 & 1 & 50 & 4.57 & -3.27 & -3.29 & -2.85 & -0.05 & -0.14 & -0.21 & 0 \\
\hline 7NAX_SP_SSH & 8 & 1 & 28 & 2.47 & -3.23 & -3.36 & -1.95 & -0.01 & -0.14 & -0.28 & -0.14 \\
\hline 7NAX_SP_ECP & 20 & 1 & 50 & 4.25 & -3.21 & -4.58 & -5.13 & 1.25 & -0.13 & -0.25 & -0.28 \\
\hline 7NAX_SP_FAA & 13 & 1 & 28 & 1.92 & -2.74 & -2.47 & -2.15 & -0.25 & -0.27 & -0.25 & -2.61 \\
\hline 7NAX_SP_TER & 26 & 1 & 3 & 4.48 & -2.74 & -2.47 & -2.15 & -0.25 & -0.27 & -0.25 & -2.61 \\
\hline 7NAX_SP_NER & 19 & 1 & 9 & 2.58 & -2.59 & -2.42 & -1.21 & -0.02 & -1.36 & -1.21 & -0.18 \\
\hline 7NAX_SP_ASC & 18 & 1 & 50 & 2 & 3.01 & 0.42 & -1.21 & 0.02 & 1.36 & -1.21 & -0.18 \\
\hline 7NAX_SP_ACA & 8 & 1 & 6 & 3.47 & 4.21 & 4.22 & 4.12 & -0.01 & 0.92 & 0.92 & -0.92 \\
\hline \multicolumn{12}{|c|}{ a CR- Cluster Rank } \\
\hline \multicolumn{12}{|c|}{${ }^{b}$ NCC - Number of conformations in this cluster } \\
\hline \multicolumn{12}{|c|}{${ }^{\mathrm{c}} \mathrm{RMSD}$ - Root Mean Square Deviation } \\
\hline \multicolumn{12}{|c|}{$\begin{array}{l}\mathrm{d} \text { BE - Binding energy is estimated of the affinity of LP complex, or is the divergence between the energy of } \\
\text { complex and the sum of energies of each molecule separately. }\end{array}$} \\
\hline \multirow{2}{*}{\multicolumn{12}{|c|}{$\begin{array}{l}\text { e FIF - Intermolecular energy is the energy between non-bounded atoms, the energy between atoms detached by } \\
3-4 \text { bonds or between atoms in variable molecules. }\end{array}$}} \\
\hline & & & & & & & & & & & \\
\hline \multicolumn{12}{|c|}{$\begin{array}{l}{ }^{\mathrm{f}} \text { DE- Desolvation energy is the electrostatic and/or van der Waals energy loss of the interaction between ligand } \\
\text { or protein and solvent upon binding. }\end{array}$} \\
\hline \multirow{3}{*}{\multicolumn{12}{|c|}{$\begin{array}{l}{ }^{g} \text { EE- Electrostatic energy changes the electrostatic non-bounded energy of ligand or protein upon binding. } \\
\text { h } \text { TE- Total energy is the sum of changes of all energetic terms included in the scoring function of ligand or } \\
\text { protein upon binding, plus the changes upon binding of the entropic terms. } \\
\text { i TE- Torsion energy is related to the dihedral term of internal energy. }\end{array}$}} \\
\hline & & & & & & & & & & & \\
\hline & & & & & & & & & & & \\
\hline \multicolumn{12}{|c|}{$\begin{array}{l}\text { Inhibition constant indicates how potent an inhibitor is; it is the concentration required to produce half- } \\
\text { maximum inhibition. }\end{array}$} \\
\hline UB - Unbound S & tem's & . & $(2)]$ & & & & & & & & \\
\hline
\end{tabular}

Levomenol's lowest binding energy docking in the 7NAX binding site form strong hydrogen bond interaction with the amino acids val111, ala112, thr110, $\arg 109$, try141 ser172, trt174, thr173 of the receptor. Similarly, for the Arachidonic acid, the amino acid binding site was glu168, thr165, try174, gln164, try141, ser174, asp168, $\arg 109$, trh110, asp171, val111. In the case of Ascaridole, amino acid binding sites were val111, thr110, $\arg 109$, ser172, asn139, ala112. It was observed in the docking the ligand $\alpha$-Turmerone showed interaction with amino acids phe140, tyr174, asn139, thr173, asp168, agr109, and for $\beta$-cymene, the amino acid tyr174, tyr141, gln167, thr173, phe140, arg109, asn139, ala112 showed the affinity. When $\beta$-Turmerone (curlone) interacted with the protein, the following amino acids thr137, $\arg 109$, ser172, asn139, thr110, phe140, ala112, val111 showed interaction. Citral showed ala84, lys104,pro40 gln38, try87, thr85 and Curcumene had thr110, $\arg 109$, val111, ala112, phe140, asn139, ser172, pro142. For Eucalyptol thr173, ser172, arg109, tyr141, thr110, val111, ala112, phe and Farnesyl acetate val111, thr110, $\arg 119$, asp171, ala112,107. In case of Germacrene his119, val111, ala112, thr110, arg168, gln107, thr173, phe140, tyr141asn139 and for Germacrone pro142, phe140, ala112, val111, lys108 ile107, arg109, asp171, thr173, gln107, ser172. For Nerolidol showed his119, phe140, ala112, thr110, val111, thr173, arg109, asp121, ser172. H bonding interaction for the ligand Sesquisabinene hydrate phe140, asn139, ala112, val111, thr110, $\arg 109$, ser172 was seen. It was observed that Terpinolene showed linkage at arg109, ser172, glu, thr173, asn139, ala112, and in Zingiberenol ala112, pro142, val111, thr110, arg109, asp174, asp168, ser172. The above results conclude that curcumin and citral have a higher interaction with the spike protein of SARS-CoV beta stain, and they can be used to inhibit the propagation of the virus. 

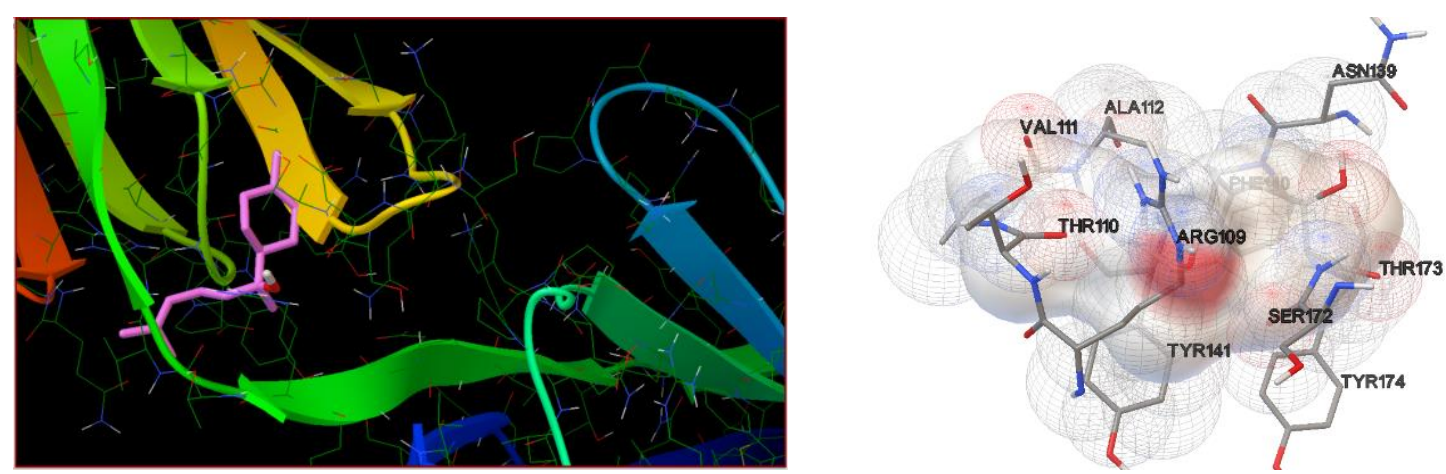

SP1- Levomenol ( $\alpha$ - Bisabolol) (ABI)
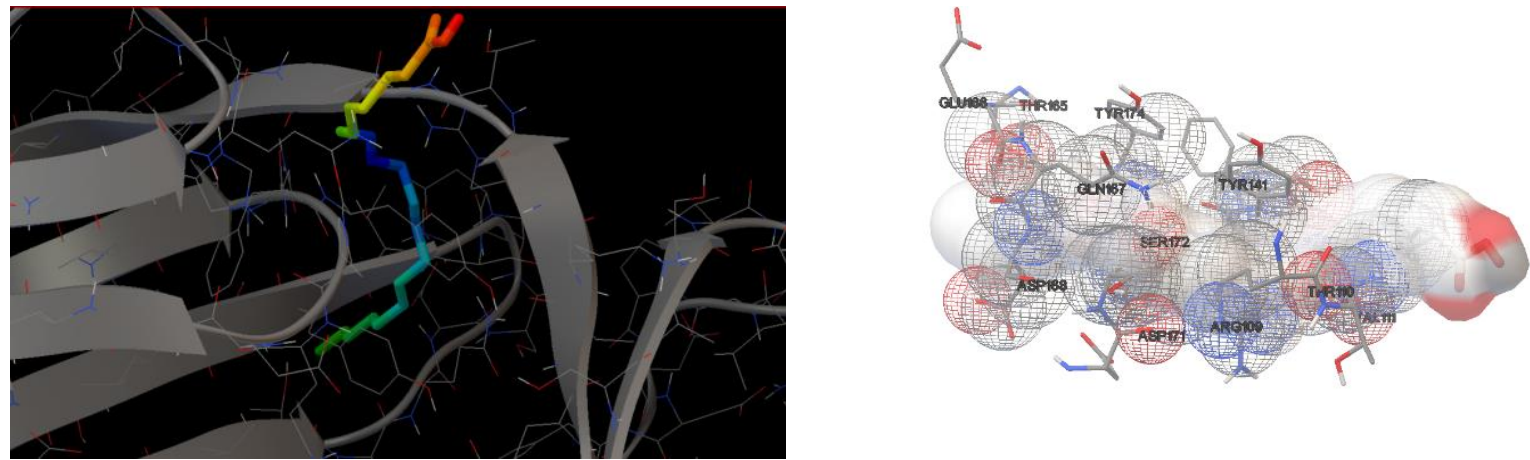

SP1- Arachidonic acid
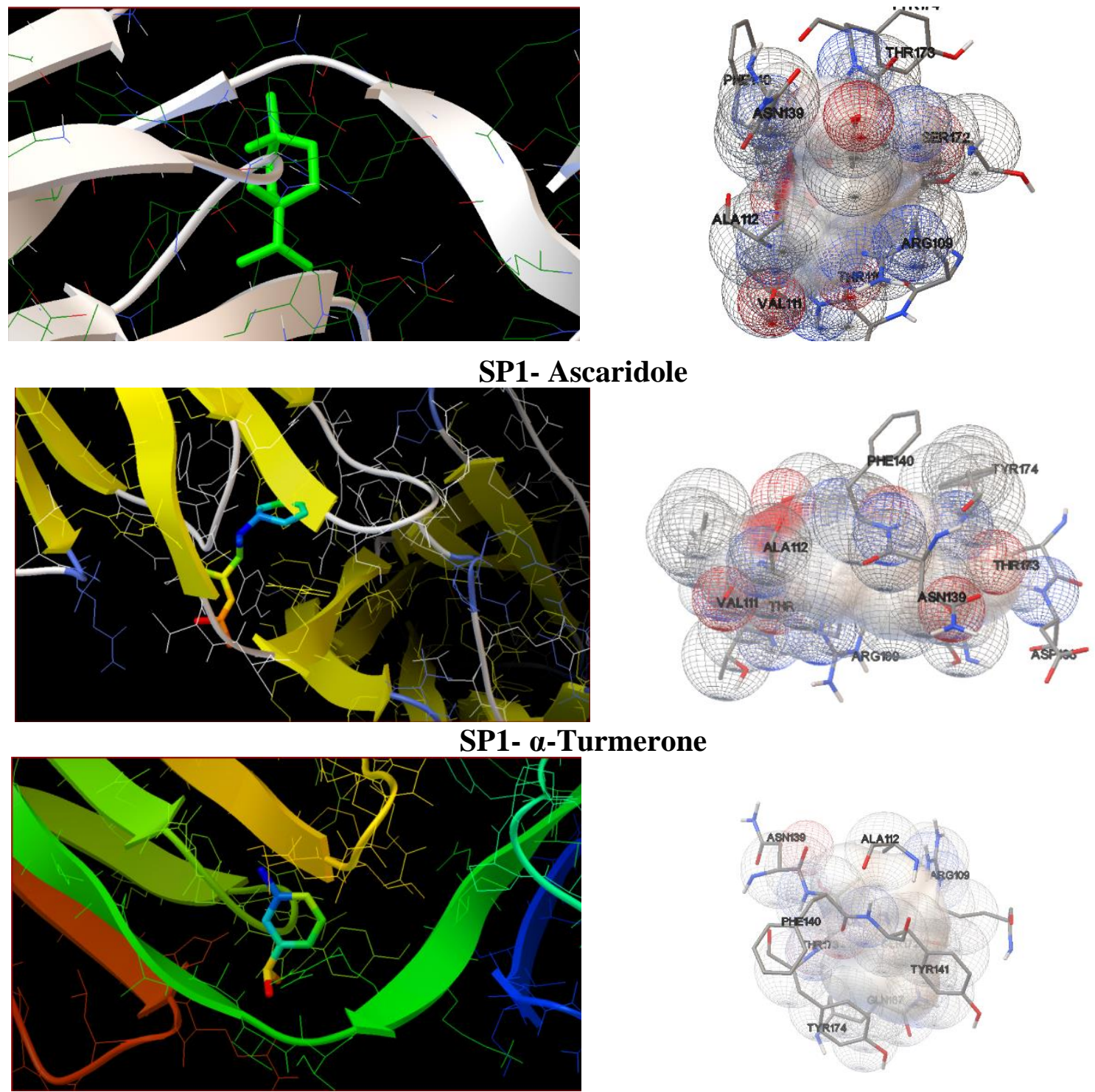

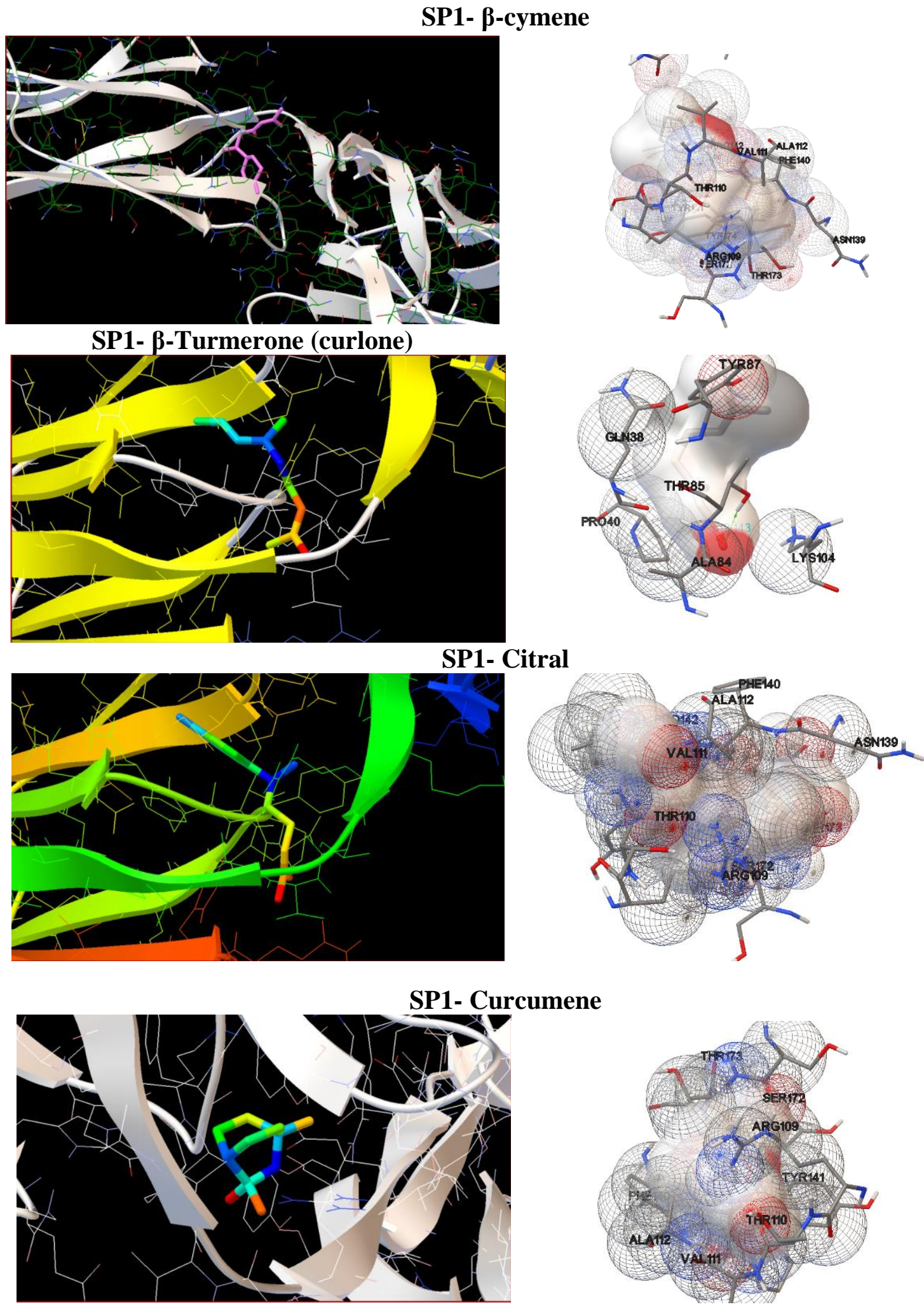


\section{SP1- Eucalyptol}
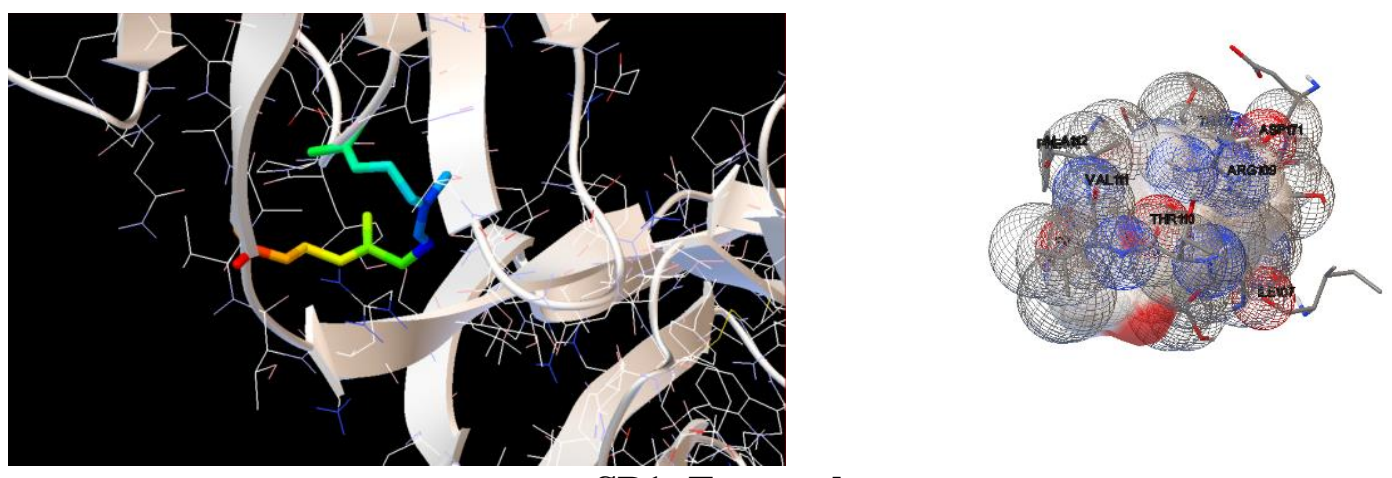

SP1- Farnesyl acetate

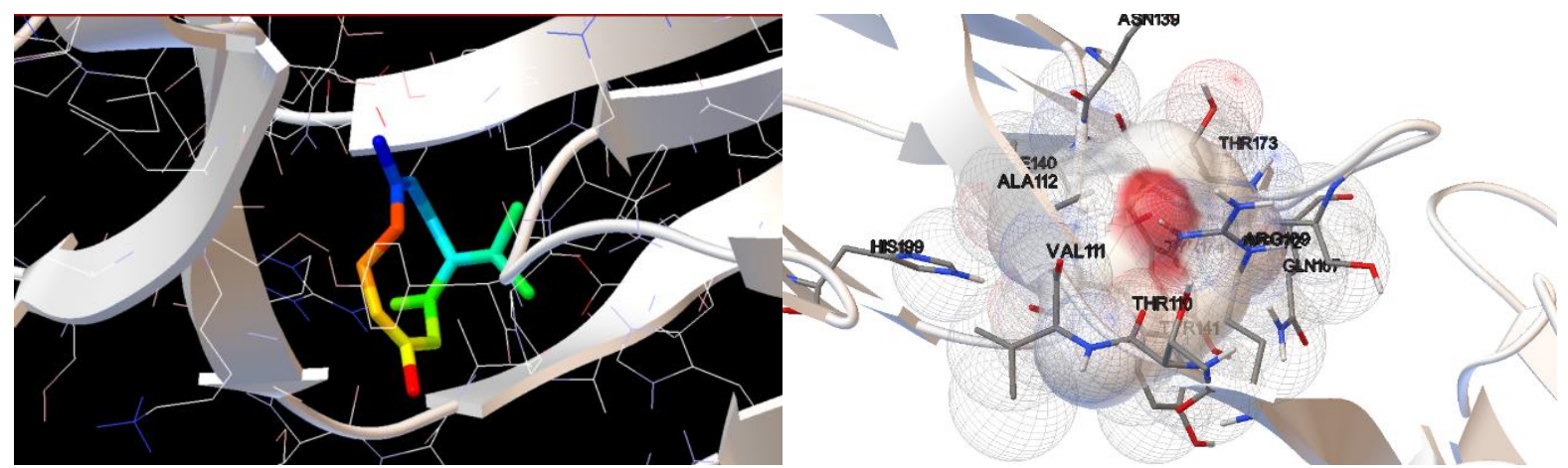

SP1- Germacrene
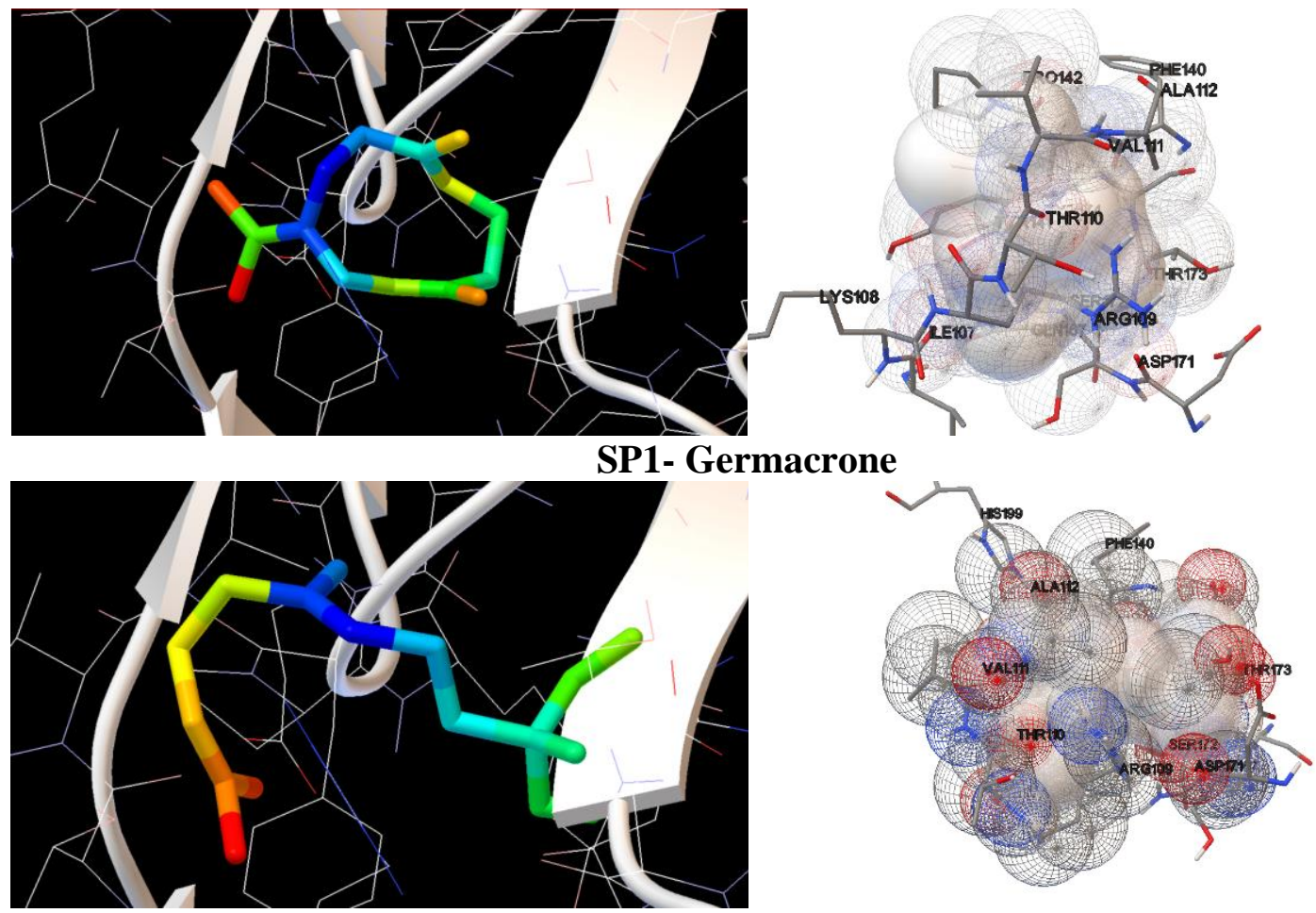
SP1- Nerolidol
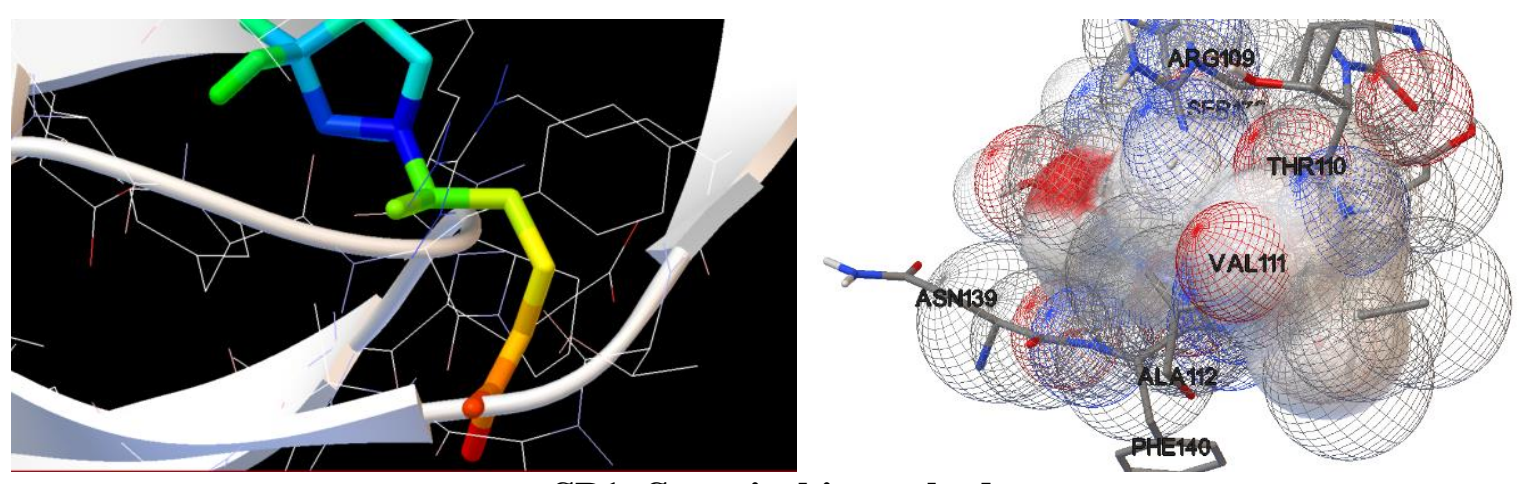

SP1- Sesquisabinene hydrate
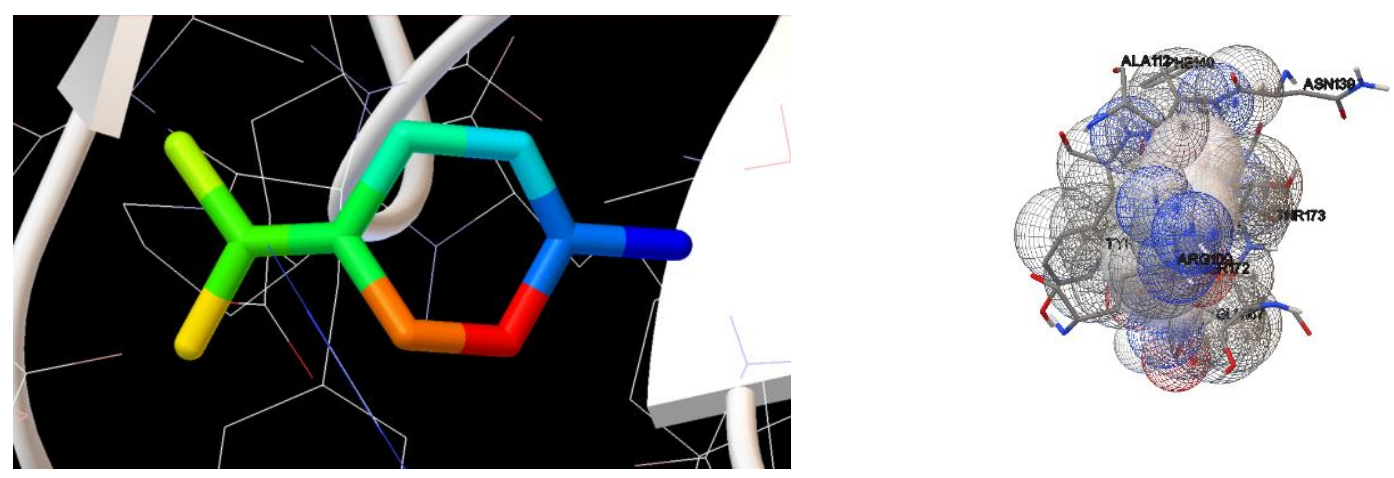

SP1- Terpinolene
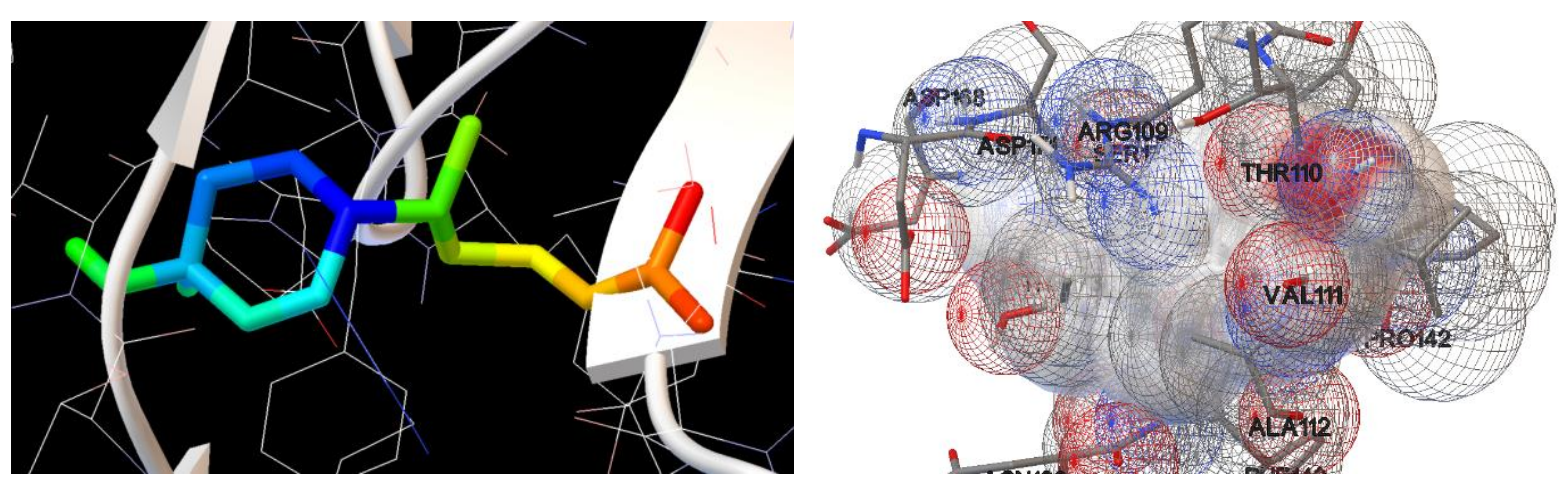

\section{SP1- Zingiberenol}

Figure 4. The interaction between SP of 7NAX with different ligands.

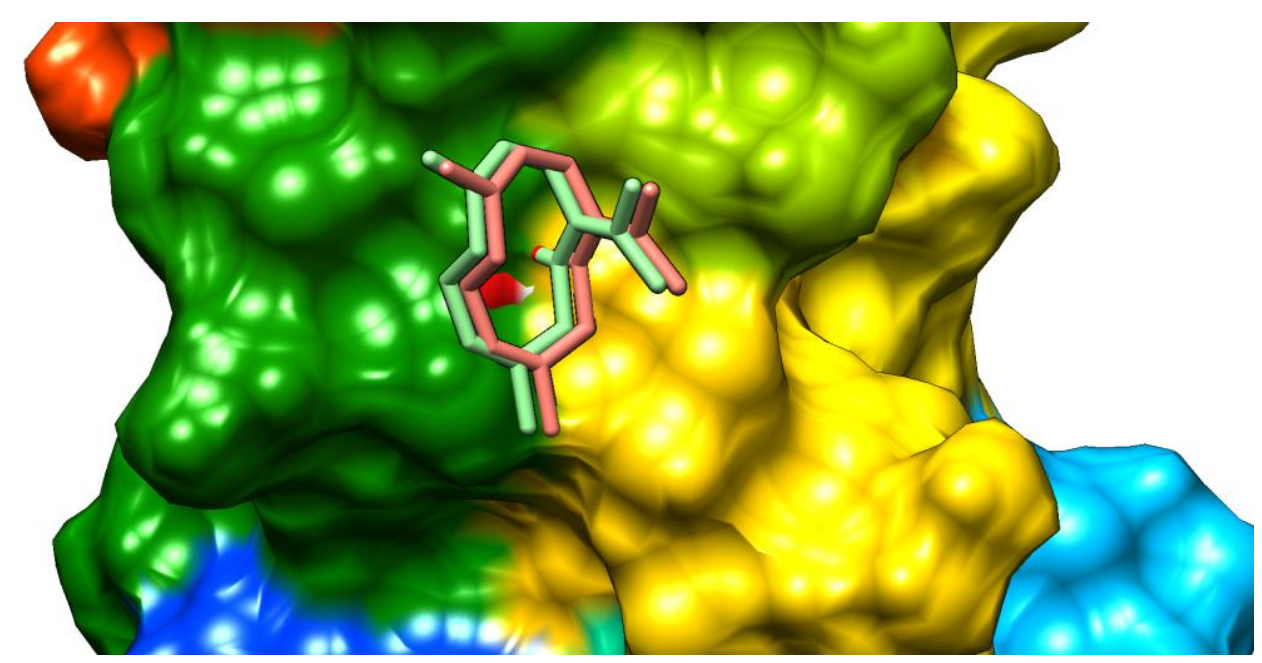

Figure 4. The cross-verified results from Chimera show the bonding of ligands on the spike protein molecule. 


\section{Conclusions}

The feasible lead elements produced from the plants showing in vitro activity against SARCoV were examined for binding towards the known types of substances extracted from Curcuma longa. The spike proteins were docked against different types of compounds, and the binding affinity towards the compound was estimated. Out of 16 compounds identified, few of them had very good interaction, and that can be suggested for further identification procedures. The Lipinsky parameters investigated showed all these components could have a potential effect against the virus. A green approach based on docking tactic was applied to this human virus SARS-CoV- 2. The ligands identified from the LCMS chromatogram were used in this in silico experiment using computational methods with austere antioxidant and therapeutic properties. These ligands can be conjugated with any drug molecules in wet-lab environments to develop a better antiviral drug against the lethal coronavirus (COVID-19). This research may facilitate the technologist and researchers to deem these ligands in their drug development and targeting investigations against SARS-CoV-2.

\section{Funding}

This research received no external funding.

\section{Acknowledgments}

The authors thank the management of Sathybama Insitute of Science and Technology for the support extended toward completing this work.

\section{Conflicts of Interest}

The authors declare no conflict of interest.

\section{References}

1. Prasansuklab, A.; Theerasri, A.; Rangsinth, P.; Sillapachaiyaporn, C.; Chuchawankul, S.; Tencomnao, T. Anti-COVID-19 drug candidates: A review on potential biological activities of natural products in the management of new coronavirus infection. J. Tradit. Complement. Med. 2021, 11, 144-157, https://doi.org/10.1016/j.jtcme.2020.12.001.

2. Khan, S.A.; Al-Balushi, K. Combating COVID-19: The role of drug repurposing and medicinal plants. $J$. Infect. Public Health 2021, 14, 495-503, https://doi.org/10.1016/j.jiph.2020.10.012.

3. Hasan, M.K.; Kamruzzaman, M.; Bin Manjur, O.H.; Mahmud, A.; Hussain, N.; Alam Mondal, M.S.; Hosen, M.I.; Bello, M.; Rahman, A. Structural analogues of existing antiviral drugs inhibit SARS-CoV-2 RNA dependent RNA polymerase: A computational hierarchical investigation. Heliyon 2021, 7, e06435, https://doi.org/10.1016/j.heliyon.2021.e06435.

4. Ekawati Tallei, T.; Geiner Tumilaar, S.; Jane Niode, N.; Johnson Kepel, B.; Idroes, R.; Effendi, Y.; Alam Sakib, S.; Bin Emran, T. Potential of Plant Bioactive Compounds as SARS-CoV-2 Main Protease (M pro ) and Spike (S) Glycoprotein Inhibitors: A Molecular Docking Study. 2020, https://doi.org/10.1155/2020/6307457.

5. Sonawane, K.D.; Barale, S.S.; Dhanavade, M.J.; Waghmare, S.R.; Nadaf, N.H.; Kamble, S.A.; Mohammed, A.A.; Makandar, A.M.; Fandilolu, P.M.; Dound, A.S.; et al. Structural insights and inhibition mechanism of TMPRSS2 by experimentally known inhibitors Camostat mesylate, Nafamostat and Bromhexine hydrochloride to control SARS-coronavirus-2: A molecular modeling approach. Informatics Med. Unlocked 2021, 24, 100597, https://doi.org/10.1016/j.imu.2021.100597.

6. Ayele, A.G.; Enyew, E.F.; Kifle, Z.D. Roles of existing drug and drug targets for COVID-19 management. Metab. Open 2021, 11, 100103, https://doi.org/10.1016/j.metop.2021.100103. 
7. Ahmed, M.; Qadir, M.A.; Shafiq, M.I.; Muddassar, M.; Samra, Z.Q.; Hameed, A. Synthesis, characterization, biological activities and molecular modeling of Schiff bases of benzene sulfonamides bearing curcumin scaffold. Arab. J. Chem. 2019, 12, 41-53, https://doi.org/10.1016/j.arabjc.2016.11.017.

8. Ahsan, A.; Liu, M.; Zheng, Y.; Yan, W.; Pan, L.; Li, Y.; Ma, S.; Zhang, X.; Cao, M.; Wu, Z.; et al. Natural compounds modulate the autophagy with potential implication of stroke. Acta Pharm. Sin. B 2020, https://doi.org/10.1016/j.apsb.2020.10.018.

9. Aisa, H.A.; Xin, X.; Tang, D. Chemical constituents and their pharmacological activities of plants from Cichorium genus. Chinese Herb. Med. 2020, 12, 224-236, https://doi.org/10.1016/j.chmed.2020.05.001.

10. Liu, Y.; Zhang, C.; Pan, H.; Li, L.; Yu, Y.J.; Liu, B.M. An insight into the in vivo imaging potential of curcumin analogues as fluorescence probes. Asian J. Pharm. Sci. 2021, https://doi.org/10.1016/j.ajps.2020.11.003.

11. Amalraj, A.; Pius, A.; Gopi, S.; Gopi, S. Biological activities of curcuminoids, other biomolecules from turmeric and their derivatives - A review. J. Tradit. Complement. Med. 2017, 7, 205-233, https://doi.org/10.1016/j.jtcme.2016.05.005.

12. Temml, V.; Kutil, Z. Structure-based molecular modeling in SAR analysis and lead optimization. Comput. Struct. Biotechnol. J. 2021, 19, 1431-1444, https://doi.org/10.1016/j.csbj.2021.02.018.

13. Lotfy, G.; Said, M.M.; El Ashry, E.S.H.; El Tamany, E.S.H.; Abdel Aziz, Y.M.; Soliman, S.M.; Barakat, A. Synthesis, structure combined with conformational analysis, biological activities and docking studies of bis benzylidene cyclohexanone derivatives. J. Saudi Chem. Soc. 2017, 21, 619-632, https://doi.org/10.1016/j.jscs.2017.04.002.

14. Ezuruike, U.F.; Prieto, J.M. The use of plants in the traditional management of diabetes in Nigeria: Pharmacological and toxicological considerations. J. Ethnopharmacol. 2014, 155, 857-924, https://doi.org/10.1016/j.jep.2014.05.055.

15. Dhar, S.; Bhattacharjee, P. Promising role of curcumin against viral diseases emphasizing COVID-19 management: A review on the mechanistic insights with reference to host-pathogen interaction and immunomodulation. J. Funct. Foods 2021, 82, 104503, https://doi.org/10.1016/j.jff.2021.104503.

16. Jiao, D.; Wang, J.; Lu, W.; Tang, X.; Chen, J.; Mou, H.; Chen, Q.Y. Curcumin inhibited HGF-induced EMT and angiogenesis through regulating c-Met dependent PI3K/Akt/mTOR signaling pathways in lung cancer. Mol. Ther. - Oncolytics 2016, 3, 16018, https://doi.org/10.1038/mto.2016.18.

17. Balada, C.; Castro, M.; Fassio, C.; Zamora, A.; Marchant, M.J.; Acevedo, W.; Guzmán, L. Genetic diversity and biological activity of Curcuma longa ecotypes from Rapa Nui using molecular markers. Saudi J. Biol. Sci. 2021, 28, 707-716, https://doi.org/10.1016/j.sjbs.2020.10.062.

18. Li, L.M.; Li, J.; Zhang, X.Y. Antimicrobial and molecular interaction studies on derivatives of curcumin against Streptococcus pneumoniae which caused pneumonia. Electron. J. Biotechnol. 2016, 19, 8-14, https://doi.org/10.1016/j.ejbt.2015.09.011.

19. Gandhi, A.J.; Rupareliya, J.D.; Shukla, V.J.; Donga, S.B.; Acharya, R. An ayurvedic perspective along with in silico study of the drugs for the management of SARS-CoV-2. J. Ayurveda Integr. Med. 2020, 10-15, https://doi.org/10.1016/j.jaim.2020.07.002.

20. Bhushan, I.; Sharma, M.; Mehta, M.; Badyal, S.; Sharma, V.; Sharma, I.; Singh, H.; Sistla, S. Bioactive compounds and probiotics-a ray of hope in COVID-19 management. Food Sci. Hum. Wellness 2021, 10, 131-140, https://doi.org/10.1016/j.fshw.2021.02.001.

21. Dourado, D.; Freire, D.T.; Pereira, D.T.; Amaral-Machado, L.; Alencar, É.N.; de Barros, A.L.B.; Egito, E.S.T. Will curcumin nanosystems be the next promising antiviral alternatives in COVID-19 treatment trials? Biomed. Pharmacother. 2021, 139, https://doi.org/10.1016/j.biopha.2021.111578.

22. Sattarinezhad, E.; Fani, N.; Bordbar, A.-K.; Hatami, P.; Abbasi Kajani, A.; Taki, M. Probing the physicochemical, antioxidant and anticancer influence of $\beta$-lactoglobulin on dietary flavonoid daidzein. Informatics Med. Unlocked 2021, 25, 100643, https://doi.org/10.1016/j.imu.2021.100643.

23. Pandey, A.; Chaturvedi, M.; Mishra, S.; Kumar, P.; Somvanshi, P.; Chaturvedi, R. Reductive metabolites of curcumin and their therapeutic effects. Heliyon 2020, 6, e05469, https://doi.org/10.1016/j.heliyon.2020.e05469.

24. Muslu, H.; Kalaycioğlu, Z.; Erdoğan, T.; Gölcü, A.; Bedia Erim, F. Synthesis, characterization, antiinflammatory evaluation, molecular docking and density functional theory studies of metal based drug candidate molecules of tenoxicam. Results Chem. 2021, 3, https://doi.org/10.1016/j.rechem.2021.100111. 
25. Mahajan, M.; Suryavanshi, S.; Bhowmick, S.; Alasmary, F.A.; Almutairi, T.M.; Islam, M.A.; Kaul-Ghanekar, R. Matairesinol, an active constituent of HC9 polyherbal formulation, exhibits HDAC8 inhibitory and anticancer activity. Biophys. Chem. 2021, 273, 106588, https://doi.org/10.1016/j.bpc.2021.106588.

26. Nirmalraj, S.; Gayathiri, E.; Sivamurugan, M.; Manivasagaperumal, R.; Jayanthi, J.; Prakash, P.; Selvam, K. Molecular docking based screening dynamics for plant based identified potential compounds of PDE12 inhibitors. Curr. Res. Green Sustain. Chem. 2021, 4, 100122, https://doi.org/10.1016/j.crgsc.2021.100122.

27. Ahmed Mahmoud Gad, E.; Elshafie Ahmed, M.; Al-Fahemi, J.H. Comparative study on quantum descriptors, molecular docking and dynamic simulation of antiviral drugs with Covid-19. Egypt. J. Pet. 2021, 30, 45-51, https://doi.org/10.1016/j.ejpe.2021.01.002.

28. Khater, I.; Nassar, A. In silico molecular docking analysis for repurposing approved antiviral drugs against SARS-CoV-2 main protease. Biochem. Biophys. Reports 2021, 27, 101032, https://doi.org/10.1016/j.bbrep.2021.101032.

29. Obafemi, C.A.; Adegbite, O.B.; Fadare, O.A.; Iwalewa, E.O.; Omisore, N.O.; Sanusi, K.; Yilmaz, Y.; Ceylan, Ü. Tryptanthrin from microwave-assisted reduction of isatin using solid-state-supported sodium borohydride: DFT calculations, molecular docking and evaluation of its analgesic and anti-inflammatory activity. Heliyon 2021, 7, e05756, https://doi.org/10.1016/j.heliyon.2020.e05756.

30. Rameshkumar, M.R.; Indu, P.; Arunagirinathan, N.; Venkatadri, B.; El-Serehy, H.A.; Ahmad, A. Computational selection of flavonoid compounds as inhibitors against SARS-CoV-2 main protease, RNAdependent RNA polymerase and spike proteins: A molecular docking study. Saudi J. Biol. Sci. 2021, 28, 448458, https://doi.org/10.1016/j.sjbs.2020.10.028.

31. Xu, J.; Gao, L.; Liang, H.; Chen, S. dong In silico screening of potential anti-COVID-19 bioactive natural constituents from food sources by molecular docking. Nutrition 2021, 82, 111049, https://doi.org/10.1016/j.nut.2020.111049.

32. Ramalakshmi, N.; Manimegalai, P.; Bhandare, R.R.; Arun Kumar, S.; Shaik, A.B. 2D-Quantitative structure activity relationship (QSAR) modeling, docking studies, synthesis and in-vitro evaluation of 1,3,4-thiadiazole tethered coumarin derivatives as antiproliferative agents. J. Saudi Chem. Soc. 2021, 25, 101279, https://doi.org/10.1016/j.jscs.2021.101279.

33. Chidambaram, S.; El-Sheikh, M.A.; Alfarhan, A.H.; Radhakrishnan, S.; Akbar, I. Synthesis of novel coumarin analogues: Investigation of molecular docking interaction of SARS-CoV-2 proteins with natural and synthetic coumarin analogues and their pharmacokinetics studies. Saudi J. Biol. Sci. 2021, 28, 11001108, https://doi.org/10.1016/j.sjbs.2020.11.038.

34. Balkrishna, A.; Mittal, R.; Sharma, G.; Arya, V. Computational insights of phytochemical-driven disruption of RNA-dependent RNA polymerase-mediated replication of coronavirus: a strategic treatment plan against coronavirus disease 2019. New Microbes New Infect. 2021, 41, 100878, https://doi.org/10.1016/j.nmni.2021.100878.

35. Saleh, M.S.M.; Siddiqui, M.J.; Alshwyeh, H.A.; Al-Mekhlafi, N.A.; Mediani, A.; Ibrahim, Z.; Ismail, N.H.; Kamisah, Y. Metabolomics-based profiling with chemometric approach to identify bioactive compounds in Salacca zalacca fruits extracts and in silico molecular docking. Arab. J. Chem. 2021, 14, 103038, https://doi.org/10.1016/j.arabjc.2021.103038.

36. García, R.; Hussain, A.; Koduru, P.; Atis, M.; Wilson, K.; Park, J.Y.; Toby, I.; Diwa, K.; Vu, L.; Ho, S.; et al. Identification of potential antiviral compounds against SARS-CoV-2 structural and non structural protein targets: A pharmacoinformatics study of the CAS COVID-19 dataset. Comput. Biol. Med. 2021, 133, 104364, https://doi.org/10.1016/j.compbiomed.2021.104364.

37. Jairajpuri, D.S.; Hussain, A.; Nasreen, K.; Mohammad, T.; Anjum, F.; Tabish Rehman, M.; Mustafa Hasan, G.; Alajmi, M.F.; Imtaiyaz Hassan, M. Identification of natural compounds as potent inhibitors of SARSCoV-2 main protease using combined docking and molecular dynamics simulations. Saudi J. Biol. Sci. 2021, 28, 2423-2431, https://doi.org/10.1016/j.sjbs.2021.01.040.

38. Metuge, J.A.: Ntie-Kang, F.: Ngwa, V.F.: Babiaka, S.B.: Samje, M.: Cho-Ngwa,F.: Molecular modeling of plant metabolites with anti-Onchocerca activity. Medicinal Chemistry Research. 2014, 21, 24(5):2127-41, http://dx.doi.org/10.1007/s00044-014-1280-x 